\title{
Effects of single and combined microalgae on larval growth, development and survival of the commercial sea cucumber Holothuria spinifera Theel
}

\author{
P S Asha \& P Muthiah \\ Tuticorin Research Centre of Central Marine Fisheries Research Institute. Tuticorin. Tamil Nadu, India
}

Correspondence: P S Asha, Tuticorin Research Centre of Central Marine Fisheries Research Institute, South Beach Road Extension. Karapad,Tuticorin 628001,Tamil Nadu. India. E-mail: ashasanil@yahoo.com

\begin{abstract}
The results of the study on the suitable algal feed for the mass rearing of holothurian larvae through hatchery system are presented. Auricularia larvae. after $48 \mathrm{~h}$ of fertilization, obtained from induced spawning of Holothuria spinifera, were fed with different algae Isochrysis galbana, Nanochloropsis salina, Paylova lutheri, Tetraselmis chuii and Chaetoceros calcitrans as well as I. galbana $+C$. calcitrans to ascertain the effect of single and combined microalgal diet. The rate of feeding was $2 \times 10^{4}$ cells larvae $^{-1} \cdot$ day $^{-1}$ for a period of 9-12 days. The growth rate of $59 \mu \mathrm{m}$ day $^{-1}$ with $90 \%$ and $43 \mu \mathrm{m}$ day ${ }^{-1}$ with $100 \%$ occurrence of late auricularia in the larvae fed with $C$. calcitrans alone and I. galbana $+C$. calcitrans, respectively, indicated that C.calcitrans itself or in combination with I. galbana is the effective feed for the larvae of $H$. spinifera.
\end{abstract}

Keywords: Holothuria spinifera, Auricularia, Isochrysis galbana. Chaetoceros calcitrans

\section{Introduction}

As in many countries of Indo-Pacific areas, dried holothurians are an important export commodity in India also. Because of increasing demand and inadequate fishery management, the sea cucumber resources are overexploited; hence. the Ministry of Environment, Government of India, has banned both fishery and export of 'beche-de-mer' from India since 2001. The release of hatchery-produced juveniles into their natural habitat is being considered as a suitable method to enhance the wild stock for sustainable yield (Munro \& Bell 1997; Yanagisawa 1998; Battaglene \& Bell 1999).
In India, the 'beche-de-mer' industry mainly depends on Holothuria scabra and Holothuria spinifera (Chellaram. Samuel \& Patterson Edward 2003). James and Badrudeen (1997) estimated an annual landing of $460 \mathrm{t}$ of fresh $\mathrm{H}$. spinifera along the south-east coast of India. Considering the role of $H$. spinifera in the commercial fishery and indiscriminate exploitation. hatchery production of juveniles and subsequent reseeding to natural habitat are the alternatives for natural as well as in-captive stock enhancement.

The success of large-scale seed production of sea cucumber through hatchery techniques mainly depends on suitable larval feed. Generally, nanoflagellates of Chryophyceae or Haptophyceae either singly or in combination are provided for the larvae of sea cucumbers (James, Gandhi, Palaniswamy \& Rodrigo 1994). Chen and Chian (1990), James, Rajapandian. Gopinathan and Baskar (1994) and Morgan (2001) reared the larvae of H. scabra and Actinopyga echinites with a higher survival and growth rate by providing Isochrysis galbann as feed. Ito and Kitamura (1997) reared the larvae of Stichopus japonicus with Chatoceros calcitrans. James, Rajapandian et al. (1994) and Battaglene (1999) reported that mixed algae dominated by $C$. calcitrans enhanced the larval growth of H. scabra.

Although the larvae of $H$. spinifera were reared successfully by providing a mixture of I. galbana, C. calcitrans and Nanochloropsis salina by Asha and Muthiah (2002), the suitability of other single and combined algal feed was not tested. The present work was initiated to assess the suitability of various microalgal feed either single or combined. for the mass rearing of $H$. spinifera through a hatchery system. 


\section{Materials and methods}

The 48-h old auricularia larvae, obtained from the induced spawning of $H$. spinifera, were reared in triplicate at $0.5 \mathrm{~mL}^{-3}$ in $3 \mathrm{~L}$ plastic aquarium bowls containing sand-filtered sea water of $34.8-35.5 \mathrm{gL}^{-1}$ salinity and a temperature of $28-30{ }^{\circ} \mathrm{C}$ for both single as well as combined feed experiment. Sea water was completely changed on alternate days and only haif the quantity was changed on other days. When a complete water change was made, the larvae were retained in a $40 \mu \mathrm{m}$ sieve and transferred to a $3 \mathrm{~L}$ glass beaker. After thorough mixing, a $1 \mathrm{~mL}$ subsample was taken in a counting chamber to estimate the survival rate. The growth rate was calculated by measuring the length of 30 larvae representing 10 in each aquarium for each treatment, using a microscope fitted with a micrometer. The maintenance and mass culture of the algae were carried out following the serial dilution technique (Gopinathan, 1982). The experiment was conducted till the auricularia larvae metamorphosed into a nonfeeding doliolaria stage.

The experiment on the single algal diet was conducted for 9 days. The initial size of the larvae was $362 \pm$ $4.4 \mu \mathrm{m}$. The different algae provided were I. galbana. C. calcitrans. N. salina. Pavlova lutheri and Tetraselmis chuii. The concentration of feed given was $2 \times 10^{4}$ cells $\mathrm{mL}^{-1}$, as suggested by Morgan (2001) and Asha (2004). The larvae were fed daily and the feed was prorided as a single dose. The length of the larvae was measured on the third. fifth. seventh and ninth day.

For the combined feed experiment conducted in triplicate for 12 days, the larvae were provided with I. galbana and C. calcitrans in equal concentrations. For comparison, one set of larvae were reared with $I$. galbana alone and another with $\mathrm{C}$. calcitrans alone at a feed concentration of $2 \times 10^{4}$ cells $\mathrm{mL}^{-1}$. The initial length of the larvae was $474 \pm 7.8 \mu \mathrm{m}$. The larval length measurements were taken on the sixth, 10th and 12 th day.

From the initial values, the mean differences in the size and number of 9-day-old larvac for the single algal diet experiment and 12-day-old larvae for the combined diet experiment were considered for each treatment in the one-way analysis of variance (ANOVA). The differences between treatments were tested for significance by multiple comparisons using the SPSS 7.5 program.

\section{Results and discussion}

\section{Single algal feed}

On days 3 and 5 , the larvae fed with 1 . galbana showed the maximum growth rate of 232.4 and $97.7 \mu \mathrm{m} \mathrm{day}^{-1}$, followed by 210.9 and $66.4 \mu \mathrm{m}_{\text {day }}{ }^{-1}$ by those fed with $C$. calcitrans and 203.9 and $60.5 \mu \mathrm{m}$ day $^{-1}$ by those fed with $N$. salina respectively (Table 1). The growth rate of the larvae fed with $T$. chuii gradually reduced from 142.7 to $43.3 \mu \mathrm{m} \mathrm{day}^{-1}$ on day 5 and to $19.9 \mu \mathrm{m}$ day $^{-1}$ on day 7. On day 9, the larvae reared with $C$. calcitrans registered the maximum growth rate of $59.3 \mu \mathrm{m}_{\text {day }}{ }^{-1}$ (mean length: $836 \mu \mathrm{m}$ ) followed by $39.0 \mu \mathrm{m}$ day $^{-1}(673.7 \mu \mathrm{m})$ with $I$. galbana and $27.6 \mu \mathrm{m}$ day ${ }^{-1}$ $(563 \mu \mathrm{m})$ with $P$. lutheri. On day 9 , the growth rate was nil in the larvae reared with $N$. salina and T. chuii (Table 1) and the mean larval lengths were 355 and $289 \mu \mathrm{m}$ respectively. The one-way ANOVA on the differences in the mean growth rate of larvae fed with different single algal diet indicated statistical significance $(P<0.001)$ (Table 2$)$. In the multiple comparisons, except for the differences between $I$. galbana-fed larvae and $N$. salina-fed larvae and also $N$. salina-fed and $T$. chuii-fed larvae, all other values were significant $(P<0.001)$ (Table 2$)$.

On day $9,90 \%$ of the larvae fed with $C$. calcitrans and $43 \%$ fed with 1 . galbana reached the late auricularia stage with a lipid sphere, whereas $90 \%$ of the larvae fed with $P$. lutheri reached only up to the midstage and became deformed later. Such deformities were noticed on the fifth day with $T$, chuii and on the eighth day with the N. salina feed (Fig. 1).

Table 1 Mean $( \pm$ SE. $n=30)$ growth rate $\left(\mu \mathrm{m} \mathrm{day}^{-1}\right)$ of the auricularia of Holothuria spinifera fed with single microalgate

\begin{tabular}{lccccc}
\hline Days & I. galbana & C. calcitrans & P. lutheri & N. sallna & T. chuil \\
\hline 3 & $232.4 \pm 4.6$ & $210.9 \pm 5.1$ & $175.9 \pm 22.9$ & $203.9 \pm 29.1$ & $142.7 \pm 49.1$ \\
5 & $97.7 \pm 7.5$ & $66.4 \pm 6.9$ & $57.1 \pm 12.8$ & $60.5 \pm 10.4$ & $43.3 \pm 6.1$ \\
7 & $59.2 \pm 11.1$ & $66.1 \pm 3.6$ & $32.5 \pm 1.6$ & $31.4 \pm 11.4$ & $19.9 \pm 1.9$ \\
9 & $39.0 \pm 8.3$ & $59.3 \pm 8.8$ & $27.6 \pm 5.3$ & Nil & Nil \\
\hline
\end{tabular}

1. gallana, Isochrysis galbana; C. calcitrans, Chaetoceros calcitrans: $N$. salina, Nanochloropsis salina; $P$. Lutheri, Pavlova lutheri; $T$. chuii. Tetraselmis chit. 


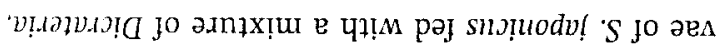

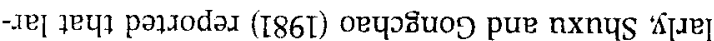

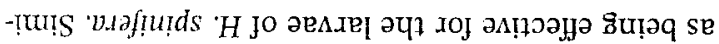

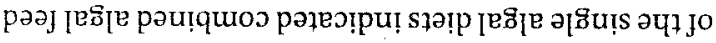

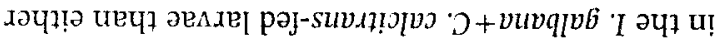

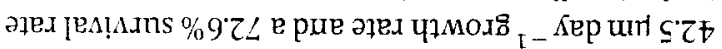

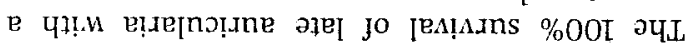

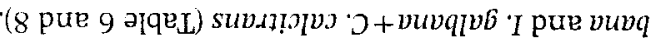
-

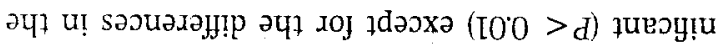

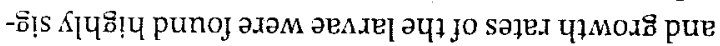

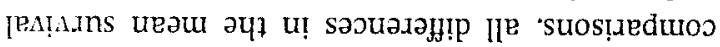

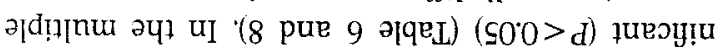

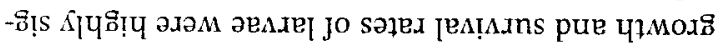

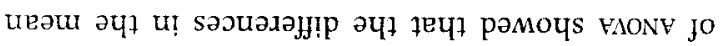

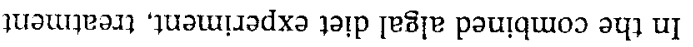

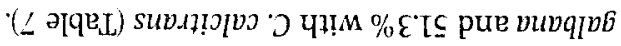

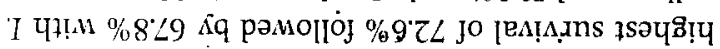

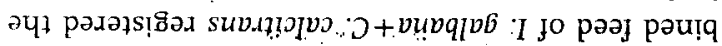

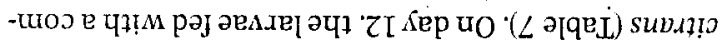

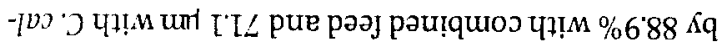

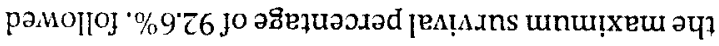

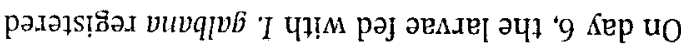

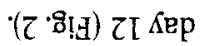

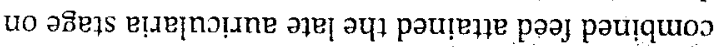

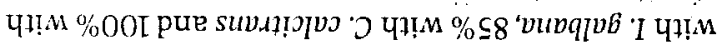

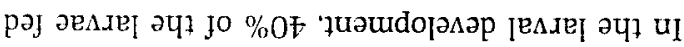

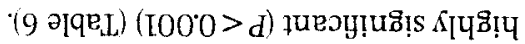

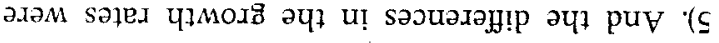

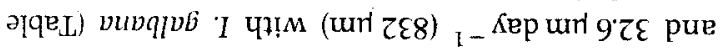

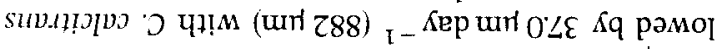

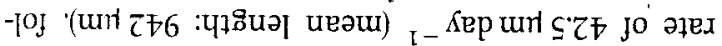

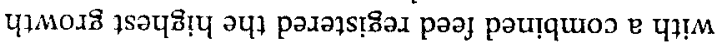

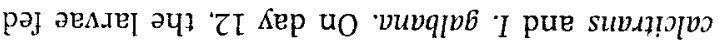

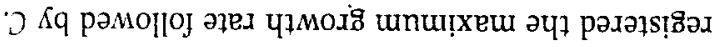

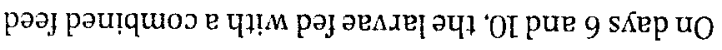

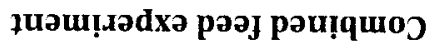

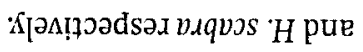

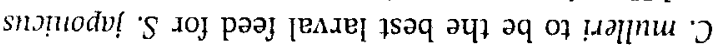
pue s!!

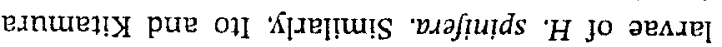

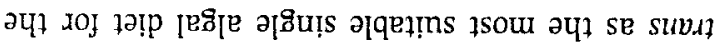

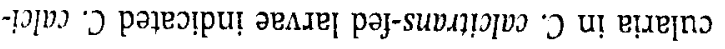

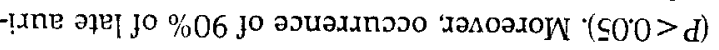

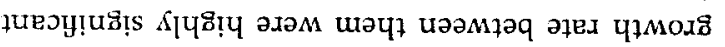

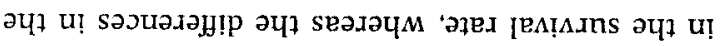

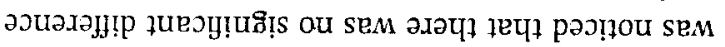

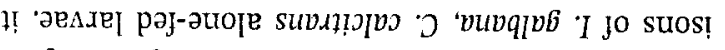

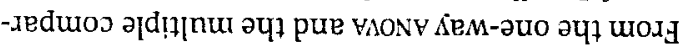

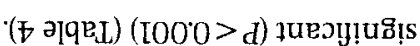

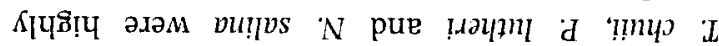

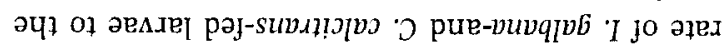

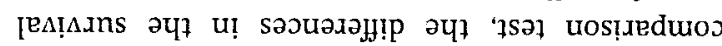

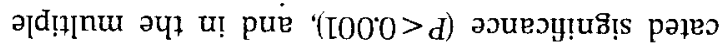

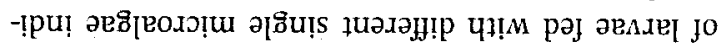

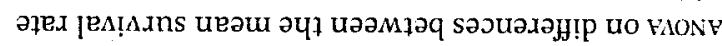

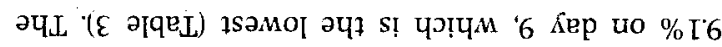

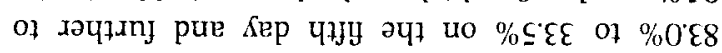

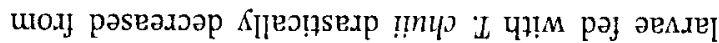

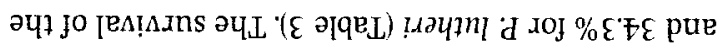

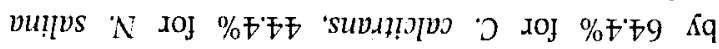

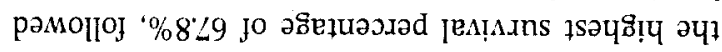

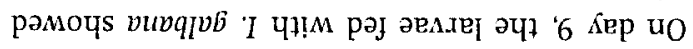

6 Kep uo

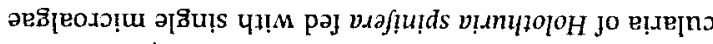

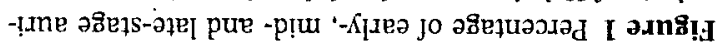

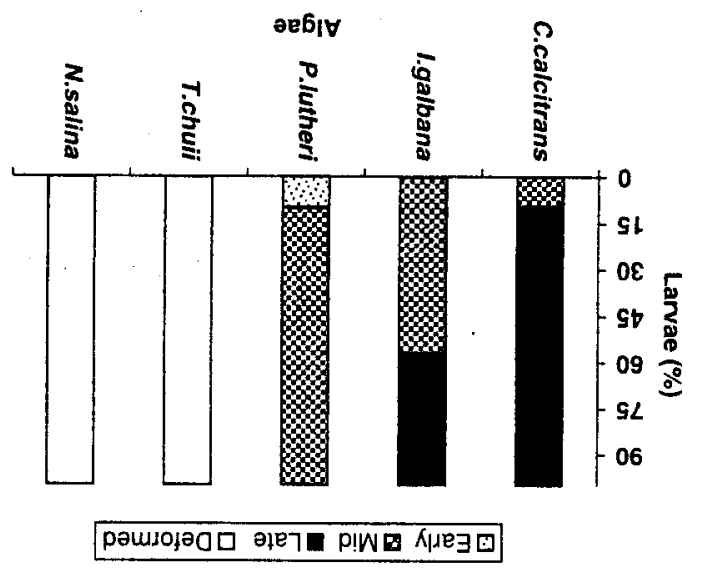

ววนวגวн!р ұие

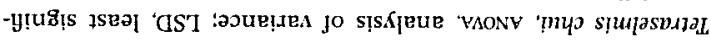

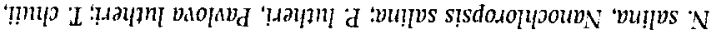

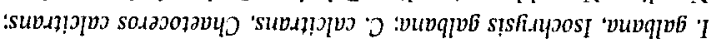

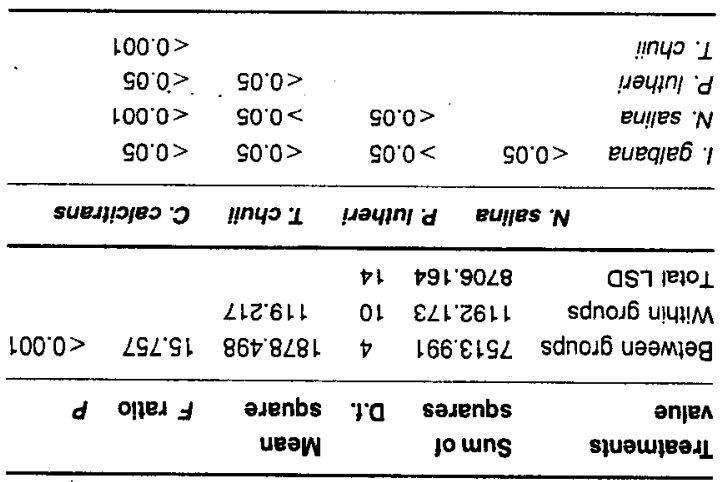

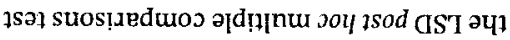

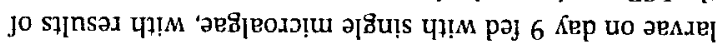

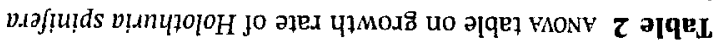


Table 2 ANova table on growth rate of Holothuria spinifera larvae on day 9 fed with single microalgae, with results of the LSD post hoc multiple comparisons test

\begin{tabular}{|c|c|c|c|c|c|c|c|}
\hline \multicolumn{2}{|l|}{$\begin{array}{l}\text { Treatments } \\
\text { value }\end{array}$} & \multicolumn{2}{|c|}{$\begin{array}{l}\text { Sum of } \\
\text { squares }\end{array}$} & D.t. & $\begin{array}{l}\text { Mean } \\
\text { square }\end{array}$ & $F$ ratio & $P$ \\
\hline Between grob & ups & 7513. & 991 & 4 & 1878.498 & 15.757 & $<0.001$ \\
\hline Within groups & & 1192. & 173 & 10 & 119.217 & & \\
\hline \multirow[t]{2}{*}{ Total LSD } & & 8706. & 164 & 14 & & & \\
\hline & \multicolumn{2}{|c|}{ N. salina } & \multicolumn{2}{|c|}{ P. lutheri } & T. chuil & \multicolumn{2}{|c|}{ C. ca/citrans } \\
\hline 1. galbana & \multicolumn{2}{|c|}{$<0.05$} & \multicolumn{2}{|c|}{$>0.05$} & $<0.05$ & \multicolumn{2}{|l|}{$<0.05$} \\
\hline N. salina & & & \multicolumn{2}{|c|}{$<0.05$} & $>0.05$ & \multicolumn{2}{|l|}{$<0.001$} \\
\hline P. lutheri & & & & & $<0.05$ & \multicolumn{2}{|l|}{$<0.05$} \\
\hline T. chuii & & & & & & $<0.001$ & \\
\hline
\end{tabular}

I. galbana, Isochrysis galbana; C. calcitrans, Chaetoceros calcitrans; N. salina, Nanochloropsis salina; P. lutheri, Pavlova lutheri; T. chuii, Tetraselmis chui, ANOVA, analysis of variance; LSD, least significant difference.

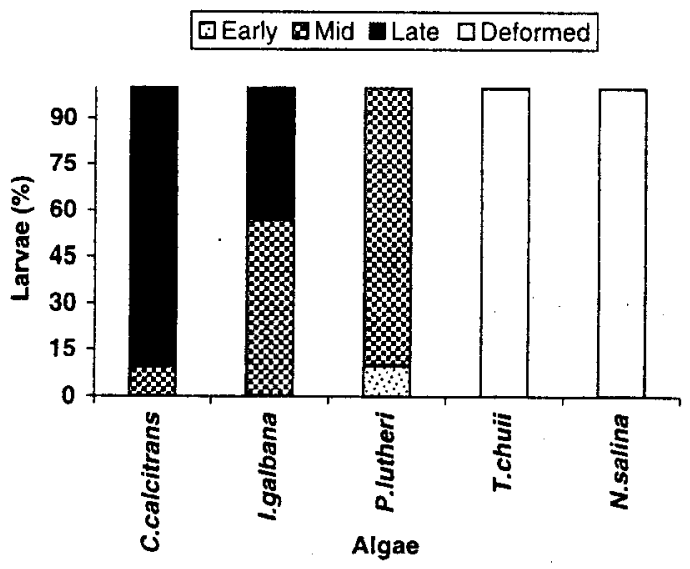

Figure 1 Percentage of early-, mid- and late-stage auricularia of Holothuria spinifera fed with single microalgae on day 9.

On day 9, the larvae fed with I. galbana showed the highest survival percentage of $67.8 \%$, followed by $64.4 \%$ for C. calcitrans, $44.4 \%$ for $N$. salina and $34.3 \%$ for $P$. lutheri (Table 3). The survival of the larvae fed with $T$. chuii drastically decreased from $83.0 \%$ to $33.5 \%$ on the fifth day and further to $9.1 \%$ on day 9, which is the lowest (Table 3). The Anovi on differences between the mean survival rate of larvae fed with different single microalgae indicated significance $(P<0.001)$, and in the multiple comparison test, the differences in the survival rate of $I$. galbana-and C. calcitrans-fed larvae to the T. chuii, $P$. lutheri and $N$. salina were highly significant $(P<0.001)$ (Table 4$)$.
From the one-way ANOvA and the multiple comparisons of I. galbana, C. calcitrans alone-fed larvae. it was noticed that there was no significant difference in the survival rate, whereas the differences in the growth rate between them were highly significant $(P<0.05)$. Moreover, occurrence of $90 \%$ of late auricularia in $C$. calcitrans-fed larvae indicated $C$. calcitrans as the most suitable single algal diet for the larvae of $H$. spinifera. Similarly. Ito and Kitamura (1997) and Battaglene (1999) found C. gracilis and C. mulleri to be the best larval feed for $S$. japonicus and $H$. scabra respectively.

\section{Combined feed experiment}

On days 6 and 10, the larvae fed with a combined feed registered the maximum growth rate followed by $C$. calcitrans and I. galbana. On day 12, the larvae fed with a combined feed registered the highest growth rate of $42.5 \mu \mathrm{m}_{\mathrm{day}^{-1}}{ }^{-1}$ (mean length: $942 \mu \mathrm{m}$ ). followed by $37.0 \mu \mathrm{m}$ day $^{-1}(882 \mu \mathrm{m})$ with $C$. calcitrans and $32.6 \mu \mathrm{m} \mathrm{day}^{-1}(832 \mu \mathrm{m})$ with $I$. galbana (Table 5). And the differences in the growth rates were highly significant $(P<0.001)$ (Table 6).

In the larval development. $40 \%$ of the larvae fed with I. galbana, $85 \%$ with C. calcitrans and $100 \%$ with combined feed attained the late auricularia stage on day 12 (Fig. 2).

On day 6 , the larvae fed with I. galbana registered the maximum survival percentage of $92.6 \%$, followed by $88.9 \%$ with combined feed and $71.1 \mu \mathrm{m}$ with C. calcitrans (Table 7). On day 12. the larvae fed with a combined feed of $I$. galbaina $+C$. "calcitrans registered the highest survival of $72.6 \%$ followed by $67.8 \%$ with $I$. galbana and $51.3 \%$ with C. calcitrans (Table 7 ).

In the combined algal diet experiment, treatment of ANOVA showed that the differences in the mean growth and survival rates of larvae were highly significant $(P<0.05)$ (Table 6 and 8 ). In the multiple comparisons, all differences in the mean survival and growth rates of the larvae were found highly significant $(P<0.01)$ except for the differences in the mean survival rate between the larvae fed with $I$. galbana and I. galbana + C. calcitrans (Table 6 and 8 ).

The 100\% survival of late auricularia with a $42.5 \mu \mathrm{m}$ day ${ }^{-1}$ growth rate and a $72.6 \%$ survival rate in the I. galbana + C. calcitrans-fed larvae than either of the single algal diets indicated combined algal feed as being effective for the larvae of $H$. spinifera. Similarly, Shuxu and Gongchao (1981) reported that larvae of $S$. japonicus fed with a mixture of Dicrateria, 
Table 3 Mean $( \pm$ SE. $n=30$ ) survival percentage of the auricularia of Holothurin spinifera fed with single microalgae

\begin{tabular}{llllll}
\hline Days & l. galbana & C. calcitrans & N. salina & P. lutheri & T. chuii \\
\hline 3 & $87.4 \pm 7.3$ & $92.7 \pm 5.1$ & $79.6 \pm 1.4$ & $85.5 \pm 2.2$ & $83.0 \pm 6$ \\
5 & $83.3 \pm 7.1$ & $84.9 \pm 7.3$ & $74.5 \pm 1.5$ & $67.0 \pm 8.1$ & $33.5 \pm 10.7$ \\
7 & $73.9 \pm 8.6$ & $78.9 \pm 5.1$ & $65.1 \pm 2.5$ & $50.1 \pm 6.8$ & $17.3 \pm 8.1$ \\
9 & $67.8 \pm 3.6$ & $64.4 \pm 7.2$ & $44.4 \pm 6.8$ & $34.3 \pm 7.6$ & $9.1 \pm 6.2$ \\
\hline
\end{tabular}

I. galbana. Isochrysis galbana; C. calcitrans. Chaetoceros calcitrans: N. salina. Nanochloropsis salina; P. lutheri. Pavlova lutheri: T. chuii. Tetraselmis chui.

Table 4 ANONA table on numbers of Holothuria spinifera larvae surviving on day 9 fed with single microalgae with results of LSD post hoc multiple comparisons test

\begin{tabular}{|c|c|c|c|c|c|c|c|}
\hline \multicolumn{2}{|l|}{$\begin{array}{l}\text { Treatments } \\
\text { value }\end{array}$} & \multicolumn{2}{|c|}{$\begin{array}{l}\text { Sum of } \\
\text { squares }\end{array}$} & D.f. & $\begin{array}{l}\text { Mean } \\
\text { square }\end{array}$ & $\begin{array}{l}F \\
\text { ratio }\end{array}$ & $P$ \\
\hline \multicolumn{2}{|c|}{ Between groups } & \multicolumn{2}{|c|}{6526.824} & 4 & 1631.706 & 21.276 & $<0.001$ \\
\hline \multicolumn{2}{|c|}{ Within groups } & \multicolumn{2}{|c|}{766.940} & 10 & 76.694 & & \\
\hline \multirow[t]{2}{*}{ Total LSD } & \multicolumn{3}{|c|}{7293.764} & 14 & & & \\
\hline & \multicolumn{2}{|c|}{ N. salina } & \multicolumn{2}{|c|}{ P. Iutheri } & T. chuii & \multicolumn{2}{|c|}{ C. calcitrans } \\
\hline 1. galbana & \multicolumn{2}{|c|}{$<0.05$} & \multicolumn{2}{|c|}{$<0.001$} & $<0.001$ & \multicolumn{2}{|l|}{$>0.05$} \\
\hline \multicolumn{3}{|l|}{$N$. salina } & \multicolumn{2}{|c|}{$>0.05$} & $<0.001$ & \multicolumn{2}{|l|}{$<0.05$} \\
\hline \multicolumn{3}{|l|}{ P. lutherl } & & & $<0.05$ & \multicolumn{2}{|l|}{$<0.05$} \\
\hline \multicolumn{3}{|l|}{ T. chuii } & & & & \multicolumn{2}{|l|}{$<0.001$} \\
\hline
\end{tabular}

I. galbana. Isochrysis galbana: C. calcitrans, Chaetoceros calcitrans; N. salina. Nanochloropsis salina: P. lutheri. Pavlova lutheri; $T$. chuii, Tetraselmis chui, ANOvA analysis of variance; LSD, least significant difference.

Table 5 Mean $( \pm \mathrm{SE}, n=30)$ growth rate $\left(\mu \mathrm{m}\right.$ day $\left.^{-1}\right)$ of the auricularia larvae of Holothuria spinifera fed with combined microalgae

\begin{tabular}{cccc}
\hline Days & I. galbana & C. calcitrans & $\begin{array}{l}\text { I. galbana }+ \\
\text { C. calcitrans }\end{array}$ \\
\hline 6 & $53.5 \pm 0.9$ & $54.3 \pm 4$ & $63.9 \pm 2.8$ \\
10 & $37.5 \pm 3.9$ & $41.8 \pm 0.3$ & $47.5 \pm 0.2$ \\
12 & $32.6 \pm 0.8$ & $37.0 \pm 0.8$ & $42.5 \pm 0.7$ \\
\hline
\end{tabular}

1. galbana. Isochrysis galbana; C. calcitrans, Chaetoceros calcitrans.

Platymonas. Nitzschia. Dunaliella and Torulopsis showed better survival and growth rate than those fed with Dicrateria shanjiangensis. James. Gandhi et al. (1994) and Ramofafia. Gervis and Bell (1995) also reported combined microalgae as the suitable feed for the larvae of $H$. scabra and $H$. atra respectively. Battaglene (1999) also observed that the mixture of Rhodomonas salina and $\mathrm{C}$. mulleri is more effective for feeding the larvae of $H$. scabra than either of the microalgae alone.
Table 6 ANova table on growth rate of Holothuria spinifera larvae on day 12 fed with combined microalgae with results of LSD post hoc multiple comparisons test

\begin{tabular}{lrrrrl}
\hline $\begin{array}{l}\text { Treatments } \\
\text { value }\end{array}$ & $\begin{array}{l}\text { Sum of } \\
\text { squares }\end{array}$ & D.f. & $\begin{array}{l}\text { Mean } \\
\text { square }\end{array}$ & $\begin{array}{l}\boldsymbol{F} \\
\text { ratio }\end{array}$ & $\boldsymbol{P}$ \\
\hline $\begin{array}{l}\text { Between groups } \\
\text { Within groups }\end{array}$ & $\begin{array}{r}149.866 \\
7.397\end{array}$ & 6 & 74.933 & 60.780 & $<0.001$ \\
$\begin{array}{l}\text { Total LSD } \\
157.263\end{array}$ & 8 & & & \\
\hline & C. calcitrans & I. galbana+C. calcitrans \\
\hline $\begin{array}{l}\text { l. galbana } \\
\text { C. calcitrans }\end{array}$ & $<0.05$ & $<0.001$ & \\
\hline
\end{tabular}

I. galbana, Isochrysis galbana: C. calcitrans. Chaetoceros calcitrans, ANOVA analysis of variance; LSD, least significant difference.

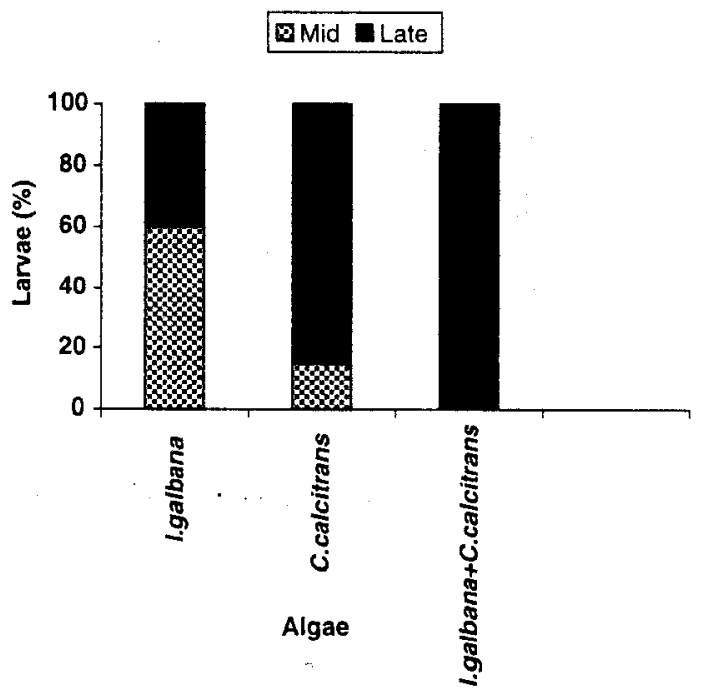

Figure 2 Percentage of mid-and late-stage auricularia of Holothuria spinifera fed with combined microalgae on day 12.

The development of seed production techniques through a hatchery system has generated significant interest in recent years as the alternate way for carrying out the stock enhancement program for the 
$9-\tau<$ u!

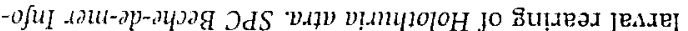

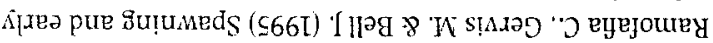

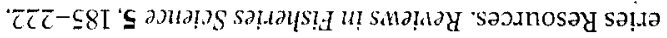

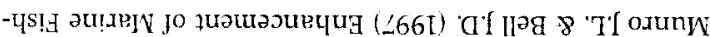

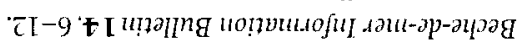

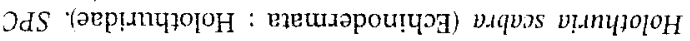

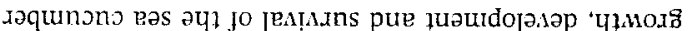

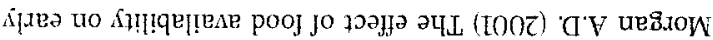

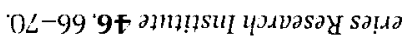

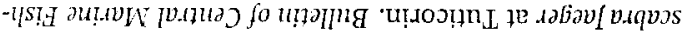

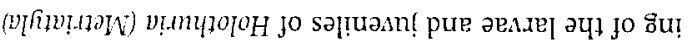

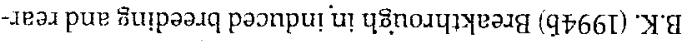

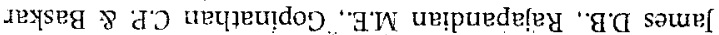

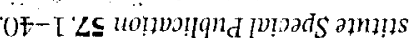

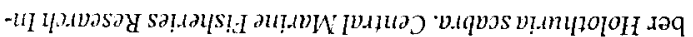

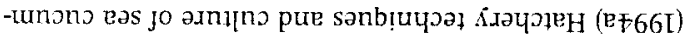

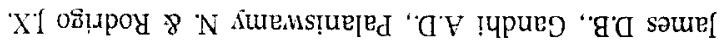
8-9 6ə I 20!clas

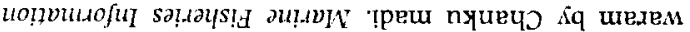

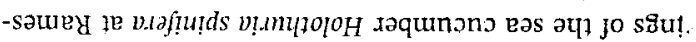

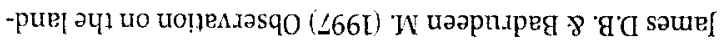

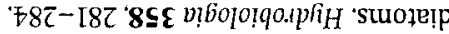

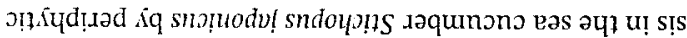

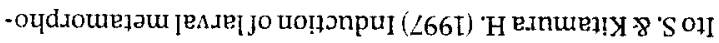

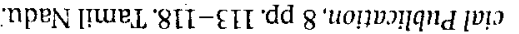

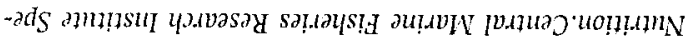

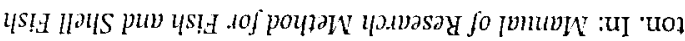

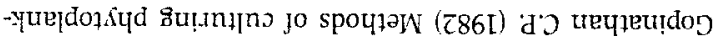

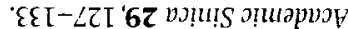

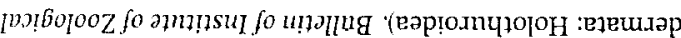

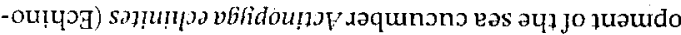

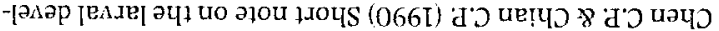

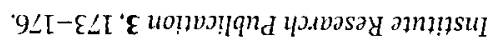

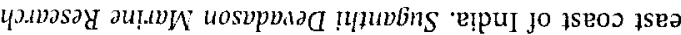
4

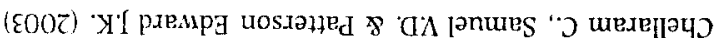
06 - $8 \angle \mathrm{f} \cdot \mathrm{dd} \times \mathrm{KemiON}$

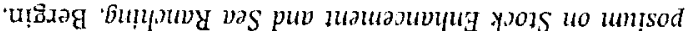

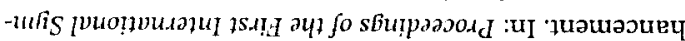

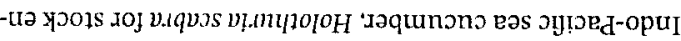

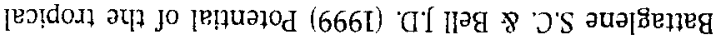

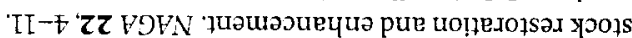

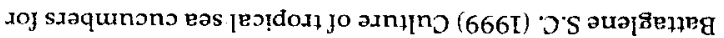

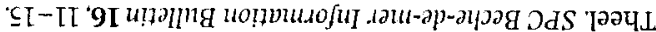

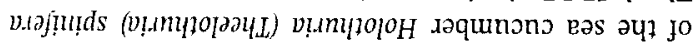
ฮี

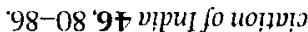

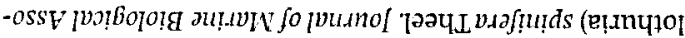

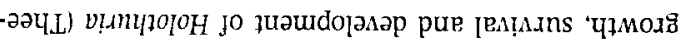

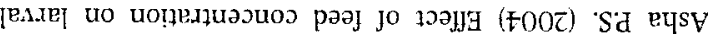

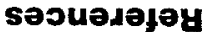

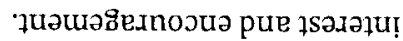

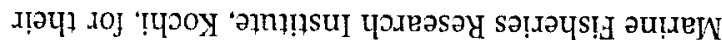

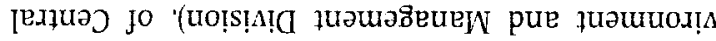

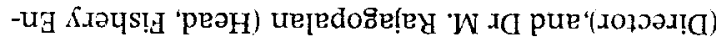

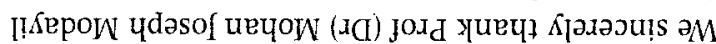

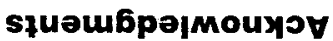

'Yoops jexnped

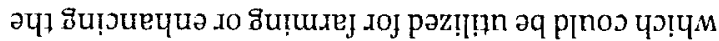

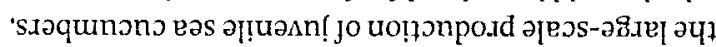

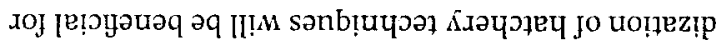

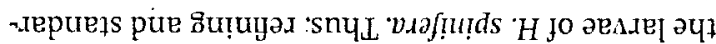

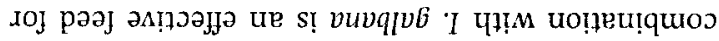

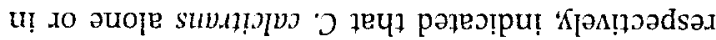

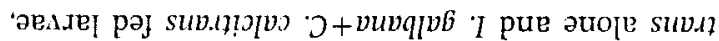

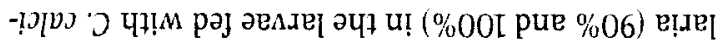

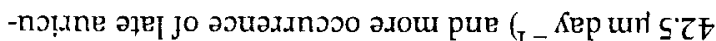

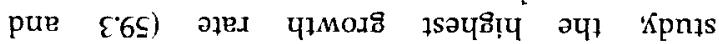

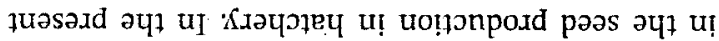

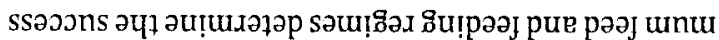

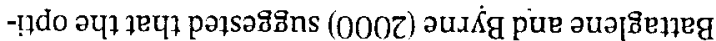

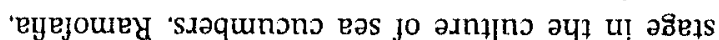

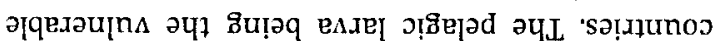

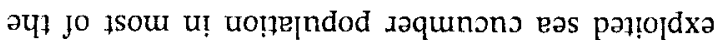

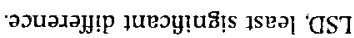

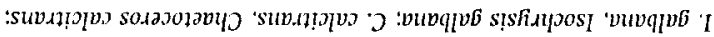

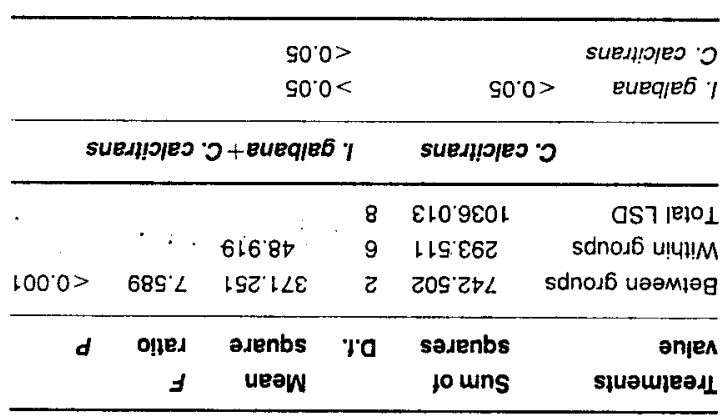

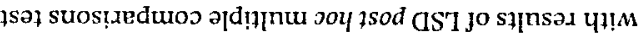

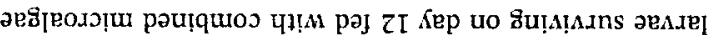

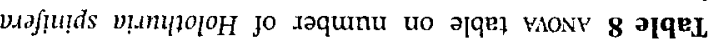

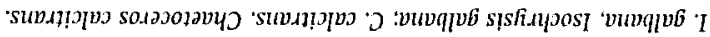

\begin{tabular}{|c|c|c|c|}
\hline$L Z \mp 9 Z L$ & $\nabla \varepsilon \mp \varepsilon \vdash s$ & $9 \angle F 8 \angle 9$ & ZI \\
\hline S't $\mp 9.08$ & $S \cdot S \neq 19$ & $\angle L \mp 60 \angle$ & of \\
\hline $9 \cdot \varepsilon \mp 6.88$ & 8. $=1 . L$ & $\vdash \cdot \varepsilon \mp 9 \cdot 26$ & 9 \\
\hline 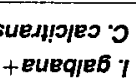 & 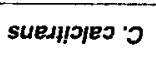 & eueqfe6 7 & skeg \\
\hline
\end{tabular}

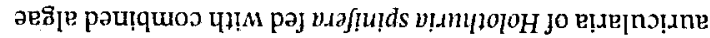

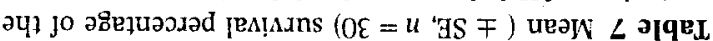


Ramofafia C., Battaglene S. \& Byrne M. (2000) Larval development in the tropical sea cucumber Holothuria scabra. In: Echinoderms 2000, Netherlands, pp. 369-375.

Shuxu X. \& Gongchao G. (1981) Experiments on southward transplantation and artificial breeding of the sea cucumber Stichopus japonicus. Journal of Fisheries China 5, 147-155.

Yanagisawa T. (1998) Aspects of the biology and culture of the sea cucumber. In: Tropical Mariculture (ed. by S. de Silva) pp. 291-308. Academic Press. London. 